\title{
The Allele Frequency Variation of Autosomal 19 Short Tandem Repeat (STR) Loci in Drug Abuser: A Pilot Study
}

xia LIN

North Sichuan Medical University

xiaoyan ZHANG

Nanchong municipal public security bureau

qin SU

Sun Yat-Sen University

Bo Jin ( $\nabla$ jinbo@nsmc.edu.cn )

North Sichuan Medical University https://orcid.org/0000-0001-9386-8471

Research article

Keywords: Substance use disorder(SUDs), Drug abuser, Addiction, Short tandem repeats (STR),

Polymorphism

Posted Date: July 23rd, 2020

DOl: https://doi.org/10.21203/rs.3.rs-44895/v1

License: (c) (i) This work is licensed under a Creative Commons Attribution 4.0 International License.

Read Full License 


\section{Abstract}

Backgrounds: Substance use disorders (SUDs) refers to drug abuse of 10 separate classes impacting seriously mental health.

Objective: This study aims to explore the genetic polymorphism of the 19 short tandem repeat (STR) loci (D19S433, D5S818, D21S11, D18S51, D6S1043, D3S1358, D13S317, D7S820, D16S539, CSF1PO, Penta D, VWA, D8S1179, TPOX, Penta E, TH01, D12S391, D2S1338, and FGA) and the risk genetic factors of substance use disorders(SUDs).

Methods: The capillary electrophoresis was applied to analyze 19 STR loci in 156 drug abusers. The data of 6,134 healthy people in a previous study were applied to contrast as the control group. The differences in the frequency of the gene were analyzed by Chi-square test.

Results: The gene distributions of 19 STR in drug addicts were consistent with hereditary rules. The frequency of vWA, FGA, Penta E was significantly different between the drug abuser and the control group $(P<0.05)$.

Conclusion: The 19 STR loci might provide highly informative polymorphic data for addicted genetic studies. Furthermore, there might be a predisposing gene for the drug abuser.

\section{Introduction}

Substance use disorders (SUDs) is described as the wild range of the disorder after taking 10 separate classes of drugs (alcohol, caffeine, cannabis, hallucinogens, inhalants, opioids, sedatives, hypnotics and anxiolytics, stimulants, tobacco) (DSM-5). It potentially led to abuser's mental health disorder, because brain's function in reward, cognitive and stress pathways [1], as well as personality traits[2] were affected by SUD. More importantly, fathers suffering from SUDs had a great impact on the mental health of their offspring[3]. In addition, the heritability was reported as $54 \%$ among drug addicts according to polygenic scores(PGSs) [4, 5]. Therefore, the individual identification and gene polymorphism of SUDs has been the key points in recent years' studies.

The premise of genetic susceptibility in persons with SUDs has been addressed in some literatures. Molecular genetics[6], transcription, and gene expression in the brain concerned with SUDs had been put forward by 1998 [7]. The gene transcription and expression variation was related with the amount of heroin use every day [8] and early age and recurrence[9]. It suggested the probability of hereditary susceptibility of substance use. Moreover, some genetic mutations of identification loci had been found to lead to inherited substance use vulnerability according to the studies of substance abuse father or his offspring[10].

As a method of genetic research, Short tandem repeat(STR) has variety and wide distribution, low mutation rate[11], high degree of polymorphism, allele, ability to identify (on each STR loci, several or 
dozens of allelic fragments), the characteristics of high sensitivity for mutation. Notably, the 19 STR includes 13 CODIS loci (CSF1PO, FGA, TH01, TPOX, VWA, D3S1358, D5S818, D7S820, D8S1179,

D13S317, D16S539, D18S51 and D21S11) and 6 STR loci in Chinese (D19S433, Penta E, D2S1338, Penta D, D6S1043 and D12S391), which were confirmed by the DNA Analysis Science Working Group (SWGDAM) [12].

The 19 STR has the higher excluding probability of paternity (probability of exclusion, PE) and probability of discrimination power (DP) in various populations [10,13-18], as well as the polymorphism test of 19 STR is economical and convenient. Especially, STR is widely used in genetic mapping, species, forensic identification, kinship analysis (especially the paternity test), even disease gene location and polymorphism and genetic disease diagnosis, susceptibility genes exploration, such as the genetic risk of gastric cancer [19]. the Penta D loci might be associated with the aggressive behaviors of schizophrenia, and its Allele 10 and genotypes 10-12 may confer a risk for schizophrenia [20]. However, there were few reports on the application of STR in SUD yet.

Consequently, we come up a hypothesis that the 19 STR loci would not only has personal identification and paternity identification, but also some significant mutation and autosomal gene STR loci polymorphism in addicts. We used blood samples from drug abusers in a certain drug treatment center in China to detect gene polymorphism of the 19 STR loci, and compare it with the reported gene polymorphism in normal Han population[21]. Some individual identification data could be furtherly understood through the characteristics of gene polymorphism in addicts in the current study, on the other hand, the predisposing gene polymorphism of SUD was explored.

\section{Methodology}

\section{Population}

Blood samples were collected from 156 unrelated individuals with drug abuse (110 males and 46 females) among the Han population in southwest, China. An informed consent was obtained from each individual for the blood collection.

\section{DNA extraction and PCR amplification}

An AGCU-EX20 STR kit (AGCU ScienTech Incorporation) was used to covers 19 STR loci and one gender loci, which is commonly selected as the polymorphism test for human genomic DNA. This kit adopts multi-color fluorescent labeling and multiple compound amplification, which can be directly amplified without lifting, template extraction and purification. Blood stains or saliva stains can be directly amplified using a filter paper or FTA card as the carrier (http://www.agcu.cn/cpzx/fyjccp/crsxl/350773.shtml).

\section{Genotyping and quality control}


The PCR products were detected by capillary electrophoresis in an ABI 3130xI Genetic Analyzer (Applied Biosystems) using the CC5 ILS 500 size standard and reference allelic ladder provided along with the AGCU-EX20 STR kit. Data analysis and genotyping were automatically performed using the GeneMapper ID v3.2 software (ABI, Forster City, USA). The internal controls (negative control and the $2800 \mathrm{M}$ DNA positive control) were genotyped along with each batch of samples to ensure the reproducibility and accuracy of the results.

\section{Data analysis}

The allelic frequencies, power of discrimination, power of exclusion, polymorphism information content and typical paternity index were calculated using the PowerStatsV12 software (http://www.promega.com/geneticidtools/). The P-values of the exact test of Hardy-Weinberg's equilibrium, expected heterozygosity and observed heterozygosity were calculated using the Arlequin software (http://cmpg.unibe.ch/software/arlequin3.5).

\section{Results}

The statistical parameters of the 19 STR loci in the drug abuser and Han population were presented in this study. In the drug abuser, the expected heterozygosity (HE) ranged from 0.598 (TH01) to 0.907 (Penta $\mathrm{E})$, and the observed heterozygosity ( $\mathrm{HO}$ ) ranged from 0.571 (TH01) to 0.910 (Penta E), while the power of discrimination (PD) varied between 0.776 (TPOX) and 0.971 (Penta E), and the combined power of discrimination for the 19 STR loci was over 0.999999999999999999999999999 999. The power of exclusion (PE) varied between 0.301 (TH01) and 0.818 (Penta E), and the combined excluding probability of paternity for the 19 loci was over 0.999999999999999999999999999 999. The polymorphism information content (PIC) varied between 0.550 (TPOX) and 0.895 (Penta E). The typical paternity index (TPI) varied between 1.353 (TPOX) and 5.75 (Penta E). Among all the studied loci, no significant deviations from the Hardy-Weinberg expectations were observed after the Bonferroni correction $(P>$ 0.0026).

The differences in allelic frequencies between the drug abuser and Han population are presented in Table 1-3. The three loci (VWA, FGA, Penta E ) presented a significant difference $(P<0.05$, bilateral test) between these two populations. However, no significant difference was found in each shared allele in the three loci between the drug abuser and Han population yet. 
Table 1

Comparison of allele frequencies at the VWA locus between subjects and controls (frequency, \%).

\begin{tabular}{|c|c|c|c|c|c|c|c|}
\hline Allele & Subjects(n = 156) & Controls(n= 6134) & $x^{2}$ & P-value & Odds ratio & $95 \% \mathrm{C}$ & \\
\hline & & & & & & low & high \\
\hline 14 & $39(25)$ & $1627(26.52)$ & .182 & .670 & .923 & .640 & 1.333 \\
\hline 15 & $4(2.564)$ & 185(3.023) & .107 & .744 & .846 & .310 & 2.308 \\
\hline 16 & $30(19.231)$ & $1060(17.286)$ & .404 & .525 & 1.140 & .761 & 1.706 \\
\hline 17 & $41(25.962)$ & $1438(23.436)$ & .682 & .409 & 1.164 & .811 & 1.671 \\
\hline 18 & $24(15.705)$ & 1171(19.084) & 1.358 & .244 & .771 & .497 & 1.196 \\
\hline 19 & $15(9.615)$ & $535(8.73)$ & .152 & .696 & 1.113 & .649 & 1.910 \\
\hline 20 & $3(1.923)$ & $101(1.65)$ & .072 & .789 & 1.171 & .367 & 3.734 \\
\hline$x^{2}$ & 1121.018 & & & & & & \\
\hline P-value & $<0.001$ & & & & & & \\
\hline
\end{tabular}


Table 2

Comparison of allele frequencies at the FGA locus between subjects and controls (frequency, \%).

\begin{tabular}{|c|c|c|c|c|c|c|c|}
\hline Allele & Subjects $(n=156)$ & Controls $(n=6134)$ & $x^{2}$ & P-value & Odds ratio & $95 \% C$ & \\
\hline & & & & & & low & high \\
\hline 18 & $4(2.244)$ & $177(2.88)$ & .056 & .813 & .886 & .325 & 2.417 \\
\hline 19 & $10(6.09)$ & $335(5.464)$ & .264 & .607 & 1.186 & .619 & 2.271 \\
\hline 20 & $6(3.846)$ & $304(4.95)$ & .400 & .527 & .767 & .336 & 1.749 \\
\hline 21 & 17(10.897) & 739(12.041) & .190 & .663 & .893 & .536 & 1.486 \\
\hline 22 & $32(20.513)$ & 1128(18.384) & .456 & .499 & 1.145 & .772 & 1.698 \\
\hline 23 & $35(22.436)$ & 1344(21.907) & .025 & .876 & 1.031 & .704 & 1.509 \\
\hline 24 & $22(14.423)$ & 1082(17.644) & 1.315 & .251 & .767 & .486 & 1.209 \\
\hline 25 & 18(11.538) & 638(10.397) & .211 & .646 & 1.124 & .683 & 1.849 \\
\hline 26 & $9(5.449)$ & $287(4.681)$ & .403 & .525 & 1.247 & .630 & 2.470 \\
\hline 27 & $4(2.244)$ & $74(1.201)$ & 2.290 & .130 & 2.155 & .778 & 5.970 \\
\hline$x^{2}$ & 65.746 & & & & & & \\
\hline P-value & $<0.001$ & & & & & & \\
\hline
\end{tabular}


Table 3

Comparison of allele frequencies at the Penta E locus between subjects and controls (frequency, \%).

\begin{tabular}{|c|c|c|c|c|c|c|c|}
\hline \multirow[t]{2}{*}{ Allele } & \multirow[t]{2}{*}{$\begin{array}{l}\text { Subjects(n = } \\
156)\end{array}$} & \multirow[t]{2}{*}{$\begin{array}{l}\text { Controls }(n= \\
6134)\end{array}$} & \multirow[t]{2}{*}{$x^{2}$} & \multirow[t]{2}{*}{$\begin{array}{l}\mathrm{P}- \\
\text { value }\end{array}$} & \multirow[t]{2}{*}{$\begin{array}{l}\text { Odds } \\
\text { ratio }\end{array}$} & \multicolumn{2}{|l|}{$95 \% \mathrm{Cl}$} \\
\hline & & & & & & low & high \\
\hline 5 & $6(3.526)$ & $325(5.302)$ & .644 & .422 & .715 & .314 & 1.629 \\
\hline 9 & $1(0.321)$ & $71(1.165)$ & .359 & .549 & .551 & .076 & 3.991 \\
\hline 10 & $4(2.244)$ & $245(4.001)$ & .818 & .366 & .633 & .232 & 1.721 \\
\hline 11 & $32(20.513)$ & $961(15.67)$ & 2.687 & .101 & 1.389 & .936 & 2.061 \\
\hline 12 & $18(11.538)$ & 689(11.236) & .014 & .905 & 1.031 & .627 & 1.695 \\
\hline 13 & $9(5.449)$ & $347(5.654)$ & .004 & .952 & 1.021 & .516 & 2.019 \\
\hline 14 & 13(8.333) & $500(8.147)$ & .007 & .935 & 1.024 & .576 & 1.821 \\
\hline 15 & $11(6.731)$ & $573(9.348)$ & .947 & .330 & .736 & .396 & 1.367 \\
\hline 16 & 13(8.013) & 487(7.939) & .032 & .857 & 1.054 & .593 & 1.874 \\
\hline 17 & $11(7.051)$ & $460(7.496)$ & .044 & .834 & .936 & .503 & 1.740 \\
\hline 18 & 12(7.372) & $419(6.837)$ & .177 & .674 & 1.137 & .626 & 2.065 \\
\hline 19 & 10(6.09) & 331(5.392) & .305 & .581 & 1.201 & .627 & 2.301 \\
\hline 20 & $6(3.526)$ & $310(5.049)$ & .465 & .495 & .751 & .330 & 1.713 \\
\hline 21 & $6(3.526)$ & 165(2.691) & .769 & .381 & 1.447 & .631 & 3.320 \\
\hline 22 & $4(2.564)$ & $100(1.635)$ & .816 & .366 & 1.588 & .577 & 4.370 \\
\hline 23 & $1(0.641)$ & $68(1.102)$ & .307 & .580 & .576 & .079 & 4.171 \\
\hline 25 & $2(1.282)$ & $12(0.199)$ & 8.085 & .004 & 6.626 & 1.470 & 29.856 \\
\hline$x^{2}$ & 144.730 & & & & & & \\
\hline $\begin{array}{l}\mathrm{P}- \\
\text { value }\end{array}$ & $<0.001$ & & & & & & \\
\hline
\end{tabular}

\section{Discussion}

In the present study, similarly with previous conclusion among different region [11, 22, 23]and ethnic population[24] in literatures, the 19 STR gene seat distribution in the drug abuser conforms to the genetic law, and so it can be applied for personal and paternity identification among drug addicts. 
Drug use, preferences and gene expression may link to some genetic variations (Gozen et al., 2016; Montesinos, Gil, \& Guerri, 2017), and the mutations were frequent in the paternal reproductive system-specially the addicted father or their offspring $[10,25]$. In the 19 STR loci, VWA, FGA, Penta E locus were identified significant associations with drug abuser among Chinese Han ethnicity in our study. Because Penta $E$ has the highest polymorphism information content (PIC), discrimination ability (PD) [26] and the most prone to mutation[27]. As well as, FGA and VWA sites are the most prone to change in size $(p=$ 0.002)[28]. Genetic variations may be just happened in abuse liability loci or other important loci, and then, produce some epigenetic variation, individual identification data, and so on, as the susceptible factors of drug abuse (Raabe, Mathies, Davies, \& Bettinger, 2014). Therefore, the associated gene polymorphism in drug abuse is necessarily worth of further explorations to provide some strategies for early prevention and treatment of SUD.

Previous research suggested that different classification of drug addiction may have a different biological basis. The reduction in excitatory neurotransmitters in the Nucleus Accumbens (NAC) may separately predicted the effects of repeated cocaine exposure[29] and changed the role of central proinflammatory immune signaling[30]. Alcohol consumption/addiction could be modulated by blocking the Toll-like 4 (TLR4) response.

Additionally, internal environment changes may lead to sequence variation and increase the heterozygosity of STR loci and become a possible mechanism of drug abuse [31, 32], namely, increased heterozygosity of some alleles may be a risk factor for susceptibility and recurrence [33], while the homozygous genotype of the gene reduces the risk of addiction $[34,35]$.

However, the risk heterozygosity and frequency of loci need to be further explored in future through increasing the cases, due to the small sample size in this study, as well as the biological risk of various drug addiction.

\section{Limitation}

The occurrence and development of SUDs is a complex process that involves multiple genes and many factors. The STR loci associated with SUDs, the difference in gender and drug types were yet not very clear in the present study because of the sample size of pilot study. However, it is greatly worth of further research after collecting a large amount of data.

\section{Conclusion}

The 19 STR loci might provide highly informative polymorphic data for addicts, and there might be predisposing genes of SUDs.

\section{Declarations}




\section{Acknowledgments}

We would like to thank Sichuan Ruisheng Biotechnology Co. Ltd.

\section{Funding information}

This work was supported by the Education Department of Sichuan Province, China (funding agency, grant number: 11SB142), the Sichuan Provincial Health and Family Planning Commission, China (funding agency, grant number: 17PJ077), the cooperation program of North Sichuan Medical College and Nanchong City China (18SXHZ0556) and Science and Technology Department Foundation of Sichuan Province, China (funding agency, grant number: 2018JY0497).

\section{Compliance with ethical standards}

\section{Conflict of interest}

The authors declare that they have no conflict of interest.

\section{Ethical approval}

Ethical approval was granted by the medical faculty of the North Sichuan medical University, China (local number 2018JY0497).

\section{References}

1. Burns JA, Kroll DS, Feldman DE, Kure Liu C, Manza P, Wiers CE, Volkow ND, Wang GJ: Molecular Imaging of Opioid and Dopamine Systems: Insights Into the Pharmacogenetics of Opioid Use Disorders. Front Psychiatry 2019, 10:626.

2. Grzywacz A, Chmielowiec J, Chmielowiec K, Mroczek B, Masiak J, Suchanecka A, Sipak-Szmigiel O, Szumilas K, Trybek G: The Ankyrin Repeat and Kinase Domain Containing 1 Gene Polymorphism (ANKK1 Taq1A) and Personality Traits in Addicted Subjects. Int J Environ Res Public Health 2019, 16(15).

3. Kendler KS, Ohlsson H, Sundquist J, Sundquist K: Maternal half-sibling families with discordant fathers: a contrastive design assessing cross-generational paternal genetic transmission of alcohol use disorder, drug abuse and major depression. Psychol Med 2019:1-8.

4. Gurriaran X, Rodriguez-Lopez J, Florez G, Pereiro C, Fernandez JM, Farinas E, Estevez V, Arrojo M, Costas J, GenPol Study G: Relationships between substance abuse/dependence and psychiatric disorders based on polygenic scores. Genes Brain Behav 2019, 18(3):e12504. 
5. Javed T, Habib R, Ghafoor S, Rumman B, Awan S, Ntepe LJM, Batool S, Nurulain SM: Association of status of acetylcholinesterase and ACHE gene 3' UTR variants (rs17228602, rs17228616) with drug addiction vulnerability in pakistani population. Chem Biol Interact 2019, 308:130-136.

6. Conneally PM, Sparkes RS: Molecular genetics of alcoholism and other addiction/compulsive disorders. General discussion. Alcohol 1998, 16(1):85-91.

7. Hope BT: Cocaine and the AP-1 transcription factor complex. Ann N Y Acad Sci 1998, 844:1-6.

8. Yanqin H, Xiaohong G, Yanyan L: Mutagenesis detection and correlation of MECP2 gene in heroin dependent population. Chinese journal of drug dependence 2012(03):179-184.

9. Perez-Rubio G, Lopez-Flores LA, Garcia-Carmona S, Garcia-Gomez L, Noe-Diaz V, Ambrocio-Ortiz E, Nava-Quiroz KJ, Morales-Gonzalez F, Del Angel-Pablo AD, Ramirez-Venegas A et al: Genetic variants as risk factors for cigarette smoking at an early age and relapse to smoking cessation treatment: $A$ pilot study. Gene 2019, 694:93-96.

10. Liu QL, Chen YF, Huang XL, Liu KY, Zhao H, Lu DJ: Population data and mutation rates of 19 STR loci in seven provinces from China based on Goldeneye DNA ID System 20A. Int J Legal Med 2017, 131(3):653-656.

11. Pan $M$, Ye Q, Ju XB, Cui H, Zhou HY: Population genetic polymorphism and mutation analysis of 19 autosomal STR loci in Jiangsu Han individuals in Eastern China. Ann Hum Biol 2019:1-7.

12. Daniels DL, Hall AM, Ballantyne J: SWGDAM developmental validation of a 19-locus Y-STR system for forensic casework. J Forensic Sci 2004, 49(4):668-683.

13. Liu J, Guo L, Qi R, Li SY, Yin JY, Zhang W, Sun Z, Tian X, Gao B: Allele frequencies of 19 autosomal STR loci in Manchu population of China with phylogenetic structure among worldwide populations. Gene 2013, 529(2):282-287.

14. Moretti TR, Moreno LI, Smerick JB, Pignone ML, Hizon R, Buckleton JS, Bright JA, Onorato AJ: Population data on the expanded CODIS core STR loci for eleven populations of significance for forensic DNA analyses in the United States. Forensic Sci Int Genet 2016, 25:175-181.

15. Zou X, Li Y, Li P, Nie Q, Wang T, Hu Y, Zhu Y, Li J, Tang R: Genetic polymorphisms for 19 autosomal STR loci of Chongqing Han ethnicity and phylogenetic structure exploration among 28 Chinese populations. Int J Legal Med 2017.

16. Tong D, Chen Y, Ou X, Chen W, Liu S, Zhang Y, Sun H: Polymorphism analysis and evaluation of 19 STR loci in the Han population of Southern China. Ann Hum Biol 2013, 40(2):191-196.

17. Whittle MR, Romano NL, Negreiros VA: Updated Brazilian genetic data, together with mutation rates, on 19 STR loci, including D10S1237. Forensic Sci Int 2004, 139(2-3):207-210.

18. Koziol P, Ciesielka M, Madro R, Krajka A: Genetic data on 19 STR loci in south-east Poland. Forensic Sci Int 2004, 139(1):89-92.

19. Laishui, YuLingzi, PanXiao Nan, liang $₫$ X-h: Association between polymorphism of 19 STR seat genes and gastric neoplasms. Journal of clinical hematology (transfusion and testing) 2016(02):267-271. 
20. Yang $\mathrm{C}, \mathrm{Ba} \mathrm{H}$, Tan X, Zhao H, Zhang S, Yu H: Association of aggressive behaviors of schizophrenia with short tandem repeats loci. Zhonghua Yi Xue Yi Chuan Xue Za Zhi 2017, 34(6):901-904.

21. Su Q, Jin B, Luo H, Li Y, Wu J, Yan J, Hou Y, Liang W, Zhang L: Population study and mutation analysis for $\mathbf{2 8}$ short tandem repeat loci in southwest Chinese Han population. $J$ Forensic Leg Med 2016, 44:10-13.

22. Wang Y, Chen F, Fu Y, Zhang S, Zhang H, Lai M, Xu E: Genetic polymorphisms of 19 autosomal STR loci in $\mathbf{3 5 1 0}$ individuals from Han population of Zhejiang province, Southeast China. Forensic Sci Int 2019, 306:110045.

23. Tao R, Wang S, Jin M, Liu Y, Zhang J, Zhang S, Li C: Forensic characteristics and phylogenetic structure of Eastern Chinese Han populations residing along the Yangtze Basin revealed by 19 autosomal STR loci. Mol Biol Rep 2019, 46(2):2541-2546.

24. Zou X, Li Y, Li P, Nie Q, Wang T, Hu Y, Zhu Y, Li J, Tang R: Genetic polymorphisms for 19 autosomal STR loci of Chongqing Han ethnicity and phylogenetic structure exploration among 28 Chinese populations. Int J Legal Med 2017, 131(6):1539-1542.

25. Martinez J, Braganholi DF, Ambrosio IB, Polverari FS, Cicarelli RMB: Mutation rates for 20 STR loci in a population from Sao Paulo state, Southeast, Brazil. Ann Hum Biol 2017, 44(7):659-662.

26. Pilav A, Pojskic N, Ahatovic A, Dzehverovic M, Cakar J, Marjanovic D: Allele frequencies of 15 STR loci in Bosnian and Herzegovinian population. Croat Med J 2017, 58(3):250-256.

27. Rodriguez JJ, Salvador JM, Calacal GC, Laude RP, De Ungria MC: Allele frequencies of 23 autosomal short tandem repeat loci in the Philippine population. Leg Med (Tokyo) 2015, 17(4):295-297.

28. Eskandarion MR, Golmohamadi T, Tabrizi AA, Nasr R, Tabasi M, Attaranzadeh A, Akbari Eidgahi MR: Optimizing denaturing HPLC as a robust technique for identification of Short Tandem Repeats (STR) in forensic medicine. J Forensic Leg Med 2019, 61:108-114.

29. Riday TT, Kosofsky BE, Malanga CJ: The rewarding and locomotor-sensitizing effects of repeated cocaine administration are distinct and separable in mice. Neuropharmacology 2012, 62(4):18581866.

30. Montesinos J, Gil A, Guerri C: Nalmefene Prevents Alcohol-Induced Neuroinflammation and Alcohol Drinking Preference in Adolescent Female Mice: Role of TLR4. Alcohol Clin Exp Res 2017, 41(7):1257-1270.

31. Barrio PA, Martin P, Alonso A, Muller P, Bodner M, Berger B, Parson W, Budowle B, Consortium D: Massively parallel sequence data of 31 autosomal STR loci from 496 Spanish individuals revealed concordance with CE-STR technology and enhanced discrimination power. Forensic Sci Int Genet 2019, 42:49-55.

32. Gettings KB, Borsuk LA, Steffen CR, Kiesler KM, Vallone PM: Sequence-based U.S. population data for 27 autosomal STR loci. Forensic Sci Int Genet 2018, 37:106-115.

33. Bach P, Zois E, Vollstadt-Klein S, Kirsch M, Hoffmann S, Jorde A, Frank J, Charlet K, Treutlein J, Beck $A$ et al: Association of the alcohol dehydrogenase gene polymorphism rs1789891 with gray matter 
brain volume, alcohol consumption, alcohol craving and relapse risk. Addict Bio/2019, 24(1):110120.

34. Al-Eitan LN, Alshudaifat KM, Anani JY: Association of the DRD4 exon III and 5-HTTLPR VNTR polymorphisms with substance abuse in Jordanian Arab population. Gene 2019:144267.

35. Moses TEH, Burmeister M, Greenwald MK: Heroin delay discounting and impulsivity: Modulation by DRD1 genetic variation. Addict Biol 2019:e12777. 